\title{
Karyological, morphological and phytochemical characteristics of medicinal plants Sophora flavescens Aiton grown from seeds collected at different localities
}

Tzu Che Lin ${ }^{1 *}$, Jih Min Sung ${ }^{2}$ and Mau Shing Yeh ${ }^{1 *}$

\begin{abstract}
Background: Dried roots of Sophora flavescens Aiton contain many phytochemicals that exhibit beneficial effects on human health. This study examined and compared the karyological, morphological and phytochemical characteristics of three $S$. flavescens populations collected from the Danda, Hualien and Yuli of Taiwan and a population collected from Gansu, China.

Results: Karyotypes of the four populations were similar, with a diploid number of $2 n=18$. The Hualien population produced more roots but with less matrine and oxymatrine contents in its root tissue than others. However, only the root of Danda population had a measurable level of naringenin. The dried root of Yuli population had greater ferric reducing antioxidant power and trolox equivalent antioxidant capacity than that of the other populations.

Conclusions: Thus, the collected S. flavescens populations, particularly the population collected from Danda, have the potential to be used in breeding programs.
\end{abstract}

Keywords: Antioxidant activity; Karyotype; Matrine; Oxymatrine; Sophora flavescens Aiton; Total phenol

\section{Background}

Sophora flavescens Aiton is a traditional Chinese medicinal herb of the Fabaceae family with wild populations distributed mainly in East Asia. The dried roots of S. flavescens, which contain many alkaloids such as matrine and oxymatrine (Liu et al., 2011), are commonly used to treat viral hepatitis, cancer, viral myocarditis, gastrointestinal hemorrhage and skin diseases (Chen et al., 2004; Ling et al., 2007; Cao et al., 2011). They also contain many flavonoids that have antioxidative potential and beneficial effects on human health (Piao et al., 2006; Jeong et al., 2008). S. flavescens is widely used in Taiwan, but the wild populations of $S$. flavescens grown in native vegetations are very limited. Therefore most $S$. flavescens plant materials are imported from China to meet the market demand. However, wild

\footnotetext{
* Correspondence: d9431201@gmail.com; msyeh@nchu.edu.tw

'Department of Agronomy, National Chung Hsing University, Taichung, ROC, Taiwan

Full list of author information is available at the end of the article
}

S. flavescens populations in China are threatened by over-harvesting (Zhao et al., 2004), thus the commercialscale cultivation of $S$. flavescens is highly desirable.

In this study, seeds of $S$. flavescens collected from three different localities in Taiwan and a locality in China were planted at the experimental farm of National Chung Hsing University (NCHU) (Taichung, Taiwan). Several morphological characteristics (plant height, number of primary branches, seed weight and root dry weight) and the microscopic observations of root, stem and leaf tissues, as well as some phytochemical characteristics (total phenol, flavonoids, matrine, oxymatrine and antioxidant activity) of field-grown S. flavescens populations collected from different localities were compared. The karyological information is useful for in species identification and analysis of hybrid populations (Michetti et al., 2010; De Souza Almeida et al., 2007), and currently little information on karyotypes of the $S$. flavescens species is available even though it is reported to be a diploid 
$(2 \mathrm{n}=18) \quad$ (Marhold, 2009). Therefore, attempts were also made to examine detailed karyotypes of the four populations. The observed variations should provide useful information concerning the potential value of these $S$. flavescens populations in producing functional substances.

\section{Methods}

Plant materials

The seeds of $S$. flavescens collected from the native vegetations of Danda, Hualien and Yuli regions of Taiwan were planted at the experimental farm of Department of Agronomy, NCHU (Taichung, Taiwan). Seeds of $S$. flavescens were also collected from Gansu, China and plants grown at NCHU were used for comparisons.

\section{Karyological analysis}

For karyological examinations, the seeds of $4 \mathrm{~S}$. flavescens populations were soaked in tap water for $24 \mathrm{~h}$. They were then put in Petri dishes lined with filter paper and were regularly watered. Petri dishes containing seeds were kept in the dark at $25^{\circ} \mathrm{C}$. Root-tips were collected when the primary roots were $1-3 \mathrm{~cm}$ long and were excised and pretreated at room temperature for $4 \mathrm{~h}$ in $0.2 \mathrm{mM}$ 8 -oxychinolin in the dark. After pretreatment the root tips were fixed in a solution of 95\% alcohol: glacial acetic acid $(3: 1, \mathrm{v} / \mathrm{v})$ solution for $24 \mathrm{~h}$. The chromosomes were stained following the procedures as described by Sharma and Gupta (1982) after hydrolysis in $1 \mathrm{~N} \mathrm{HCl}$ for $10 \mathrm{~min}$ at $60^{\circ} \mathrm{C}$. The root-tips $(0.5 \mathrm{~cm})$ were transferred to a fresh Feulgen solution for $30 \mathrm{~min}$ and then to distilled water for another $5 \mathrm{~min}$ (Kasten, 1956). The meristematic part was used for microscope examination. Chromosomes were examined at $1000 \mathrm{x}$ magnification using a microscope (BX 50, Olympus, Tokyo, Japan) equipped with a photographic attachment (E330, Olympus, Tokyo, Japan). The paired homologous chromosomes were arrayed in descending order of length. Chromosome measurements including long arm, short arm, chromosome lengths, arm ratio index, percentage of relative length and chromosome type (Levan et al., 1964) were taken from enlarged well-spread metaphase cells obtained from 10 root-tip samples of each population.

\section{Morphological examinations}

The collected S. flavescens populations were grown at the experimental farm of NCHU using the common practices. The experiment was set up following a randomized complete block design with four replicates. The seeds were sown in the nursery plots in August, 2008. The grown seedlings were then transplanted to the experimental plots. Three seedlings per hill were planted with a spacing of $85 \mathrm{~cm} \mathrm{x} 50 \mathrm{~cm}$ in each experimental plot of $10 \mathrm{~m} \times 3 \mathrm{~m}$. Ten of one-year-old plants from each experimental plot were tagged and used for agronomic characteristics (e.g., plant height, number of roots per plant and root dry weight) observations. For microscopic observations, the samples of $S$. flavescens roots $(5-10 \mathrm{~cm}$ from tap root base), stems (the fourth or fifth node from shoot apex) and leaves (the leaflet subtended on the fourth or fifth node from the shoot apex) were fixed in a FAA (formalin/glacial acetic/70\% ethanol in the ratio of 0.5:0.5:9.0) and dehydrated through the gradual ethanol series and $t$-butanol. These samples were then buried in paraffin, and sectioned with a microtome (Leica 1515, Leica Instruments, Nussloch, Germany) into slices of $15 \mu \mathrm{m}$ thickness. The section tissues were stained with a safranin-fast green solution, and then used for microscope examination (BX 50, Olympus, Tokyo, Japan).

\section{Phytochemicals determinations}

Ground root materials (1 g) sampled from each of the replicates prepared from four $S$. flavescens population were extracted with $20 \mathrm{ml}$ methanol (80:20, v/v in $\mathrm{H}_{2} \mathrm{O}$ ) for $15 \mathrm{~min}$, and the filtrate volume was re readjusted to $20 \mathrm{ml}$ with extraction reagent. The contents of total phenols in extracts were estimated using the Folin-Ciocalteau assay with a Hitachi U-2900 spectrophotometer (Tokyo, Japan) (Aguilar-Garcia et al., 2007). The absorption value was determined at $735 \mathrm{~nm}$, and gallic acid was used for constructing the standard curve. The flavonoids contents in extracts were measured using the aluminum chloride colorimetric assay as described by AbouZid and Elsherbeiny (2008). The contents of matrine and oxymatrine (alkaloids) were analyzed using high performance liquid chromatographic method as described by Li and Wang (2004). The chromatography system consisted of a high performance liquid chromatography (HPLC) (Hitachi 7200, Tokyo, Japan) equipped with an Inertsil ODS-2 column. The mobile phase comprised of A: methanol-10 mM KH $\mathrm{KH}_{2} \mathrm{PO}_{4}$-triethylamine in a ratio of 96:6:0.01 (v/v/v) and $\mathrm{B}$ : methanol. The injection volume was $20 \mu \mathrm{l}$, the flow rate was $1.0 \mathrm{ml} \mathrm{min}^{-1}$, and the UV wavelength was set at $210 \mathrm{~nm}$. Standards of matrine and oxymatrine were obtained from Wako Company (Tokyo, Japan).

\section{Antioxidant activities determinations}

To measure the ferric reducing antioxidant power (FRAP), a portion of the root extract $(0.5 \mathrm{ml})$ used for phytochemical determinations was mixed with $0.5 \mathrm{ml}$ of $0.2 \mathrm{mM}$ sodium phosphate buffer ( $\mathrm{pH}$ 6.6) containing $1.0 \% \mathrm{~K}_{3} \mathrm{Fe}(\mathrm{CN})_{6}$, and the mixture was incubated at $50^{\circ} \mathrm{C}$ for $20 \mathrm{~min}$. After adding $0.5 \mathrm{ml}$ of $1 \%$ trichloroacetic acid $(\mathrm{w} / \mathrm{v})$, the mixture was centrifuged at $200 \mathrm{~g}$ for $10 \mathrm{~min}$. The upper layer $(0.25 \mathrm{ml})$ was mixed with $3.75 \mathrm{ml}$ of de-ionized water containing $1 \%$ ferric chloride, and the absorbance was monitored at $700 \mathrm{~nm}$ in a spectrophotometer (Jeng et al., 2010). 
The trolox equivalent antioxidant capacity (TEAC) assay is based on the scavenging of 2,2'-azinobis-(3ethylbenzothiazoline-6-sulfonic acid)-radical (ABTS ${ }^{-}$). A solution of ABTS $^{\circ}$ was prepared in $0.1 \mathrm{M}$ saline phosphate buffer ( $\mathrm{pH} 7.4,0.15 \mathrm{M}$ sodium chloride) by mixing $2.5 \mathrm{mM}$ of $\mathrm{AAPH}$ with $2.0 \mathrm{mM}$ of $\mathrm{ABTS}^{2-}$ The solution was then heated for $16 \mathrm{~min}$ at $60^{\circ} \mathrm{C}$, protected from light, and stored at ambient temperature until used. To measure the radical scavenging activity, $40 \mu \mathrm{l}$ of the root extract was mixed with $1.96 \mathrm{ml}$ of $\mathrm{ABTS}^{-}$solution. Absorbance of the solution was monitored at $734 \mathrm{~nm}$, and trolox was used in the construction of the standard curve (Jeng et al., 2010).

\section{Statistical analysis}

The karyological examinations were conducted on the 10 root tips samples randomly selected from each of the S. flavescens populations. The morphological and phytochemical and antioxidant activities determinations were conducted on the field-grown $S$. flavescens populations. Data were analyzed by using the Statistical Package for Social Science (SPSS 10.0 for Windows: SPSS INC., Chicago, Il, USA). Values were given as mean \pm standard deviation and means were compared using a least significant difference (LSD) test.

\section{Results and discussion}

\section{Karyological characteristics}

The apical meristems of plant roots are frequently used to examine mitosis division and identification of chromosome arrangement, because root induction occurs rapidly and mitosis division is fast in this area (Safarnejad and Hosaini, 2005). Therefore, in the present study, root tips were used for comparing karyotypes of four S. flavescens populations. As presented in Figure 1, mitotic chromosome counts showed a diploid number of $2 n=18$ for all the $S$. flavescens populations collected from different localities. These results coincide with the previous report of Marhold (2009). Moreover, normal karyotype without satellites was observed in karyotype of populations.

Karyological characteristics of all the examined populations were similar. These results are not surprising, because the molecular assessments on internal transcribed spacer sequence showed that the tested S. flavescens populations have extremely low genetic variability (Lin et al., 2012). Since the karyological characteristics for the tested populations were similar, therefore, the karyotype data were presented as the means of the tested four populations (Table 1). In general, the karyotype of $S$. flavescens consists of two pairs of submetacentric chromosomes (chromosome pairs 7 and 8), with the arm ratio index greater than 1.71 (Table 1), according to the classification of Levan et al. (1964). The others

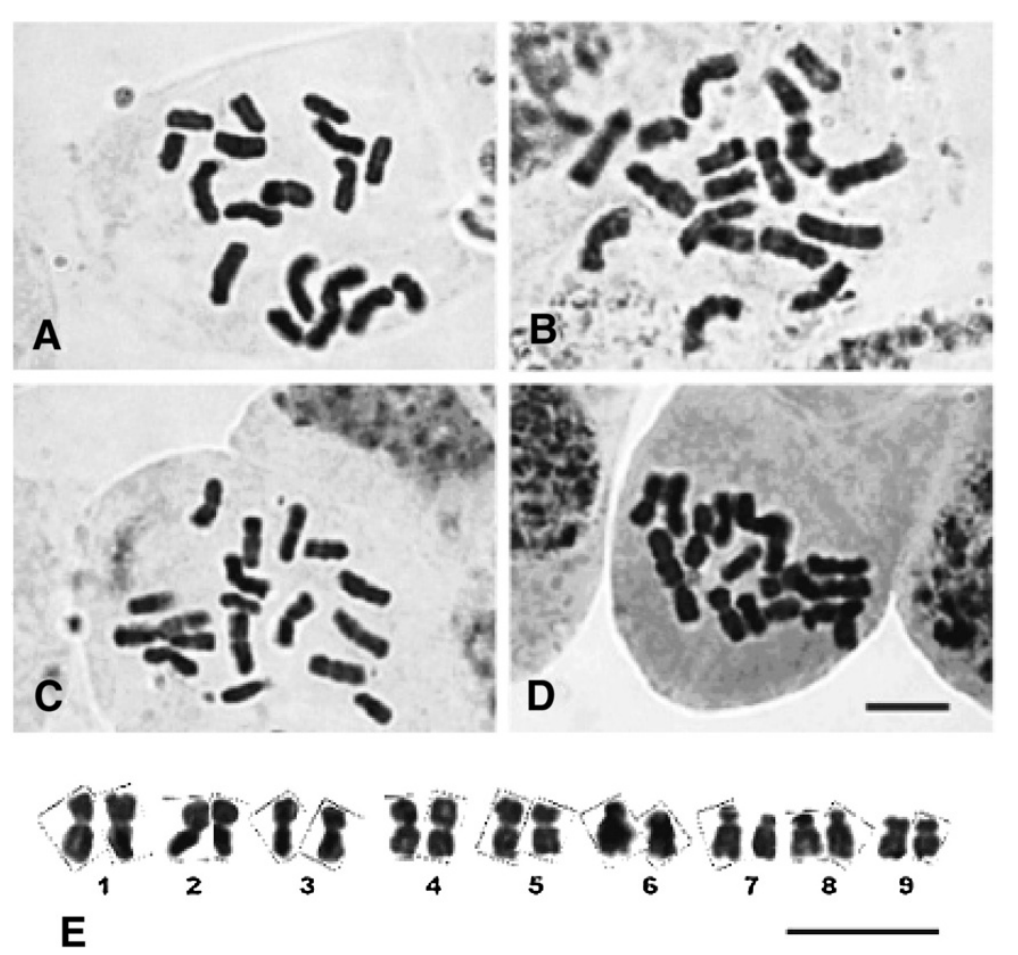

Figure 1 Mitotic metaphase chromosomes of S. flavescens populations collected from (A) Gansu, China, (B) Danda, Taiwan, (C) Hualien, Taiwan, (D) Yuli, Taiwan, scale bar $=10 \mu \mathrm{m}$, and (E) karyotype of S. flavescens population collected from Yuli, Taiwan. Scale bar $=10 \mu \mathrm{m}$. 
Table 1 Measurements of karyological characteristics of S. flavescens populations ${ }^{a}$

\begin{tabular}{|c|c|c|c|c|c|c|}
\hline Chromosome pair & Short arm $(\mu \mathrm{m})$ & Long arm $(\mu \mathrm{m})$ & Total length of chromosome $(\mu \mathrm{m})$ & $\begin{array}{c}\text { Arm ratio } \\
\text { index }\end{array}$ & $\begin{array}{c}\text { Percentage relative } \\
\text { length (\%) }\end{array}$ & $\begin{array}{c}\text { Chromosome } \\
\text { type }\end{array}$ \\
\hline 1 & $2.15 \pm 0.29$ & $3.51 \pm 0.31$ & $5.66 \pm 0.70$ & 1.63 & 7.01 & m \\
\hline 2 & $2.05 \pm 0.15$ & $2.98 \pm 0.41$ & $5.03 \pm 0.46$ & 1.45 & 6.23 & $\mathrm{~m}$ \\
\hline 3 & $2.12 \pm 0.46$ & $2.75 \pm 0.39$ & $4.87 \pm 0.55$ & 1.30 & 6.03 & $\mathrm{~m}$ \\
\hline 4 & $1.96 \pm 0.24$ & $2.73 \pm 0.38$ & $4.69 \pm 0.47$ & 1.39 & 5.81 & $\mathrm{~m}$ \\
\hline 5 & $1.85 \pm 0.21$ & $2.75 \pm 0.37$ & $4.60 \pm 0.56$ & 1.49 & 5.70 & $\mathrm{~m}$ \\
\hline 6 & $1.69 \pm 0.24$ & $2.48 \pm 0.24$ & $4.17 \pm 0.44$ & 1.46 & 5.16 & $\mathrm{~m}$ \\
\hline 7 & $1.47 \pm 0.25$ & $2.51 \pm 0.15$ & $3.98 \pm 0.36$ & 1.71 & 4.93 & sm \\
\hline 8 & $1.48 \pm 0.14$ & $2.23 \pm 0.21$ & $3.70 \pm 0.24$ & 1.87 & 4.58 & $\mathrm{~m}$ \\
\hline 9 & $1.28 \pm 0.26$ & $2.40 \pm 0.31$ & $3.68 \pm 0.35$ & 1.51 & 4.56 & $\mathrm{sm}$ \\
\hline Total & 16.04 & 24.34 & 40.38 & & & \\
\hline
\end{tabular}

Abbreviation: $m$ metacentric, sm submetacentric.

${ }^{\mathrm{a}}$ Results are shown as mean \pm standard deviation $(\mathrm{n}=10)$.

five chromosome pairs were metacentric, with the arm ratio index ranged from 1.30 to 1.63 (Table 1). The total length of chromatin was $40.38 \mu \mathrm{m}$, the longest and shortest chromosomes were estimated $5.66 \mu \mathrm{m}$ (chromosome pair 1) and $3.68 \mu \mathrm{m}$ (chromosome pair 9), respectively (Table 1 ).

\section{Morphological characteristics}

All the S. flavescens populations grew vigorously at the experimental farm of $\mathrm{NCHU}$ located in Taichung city, even though they were grown from seeds collected from different localities (Figure 2). However, significant differences in the agronomic characteristics were found
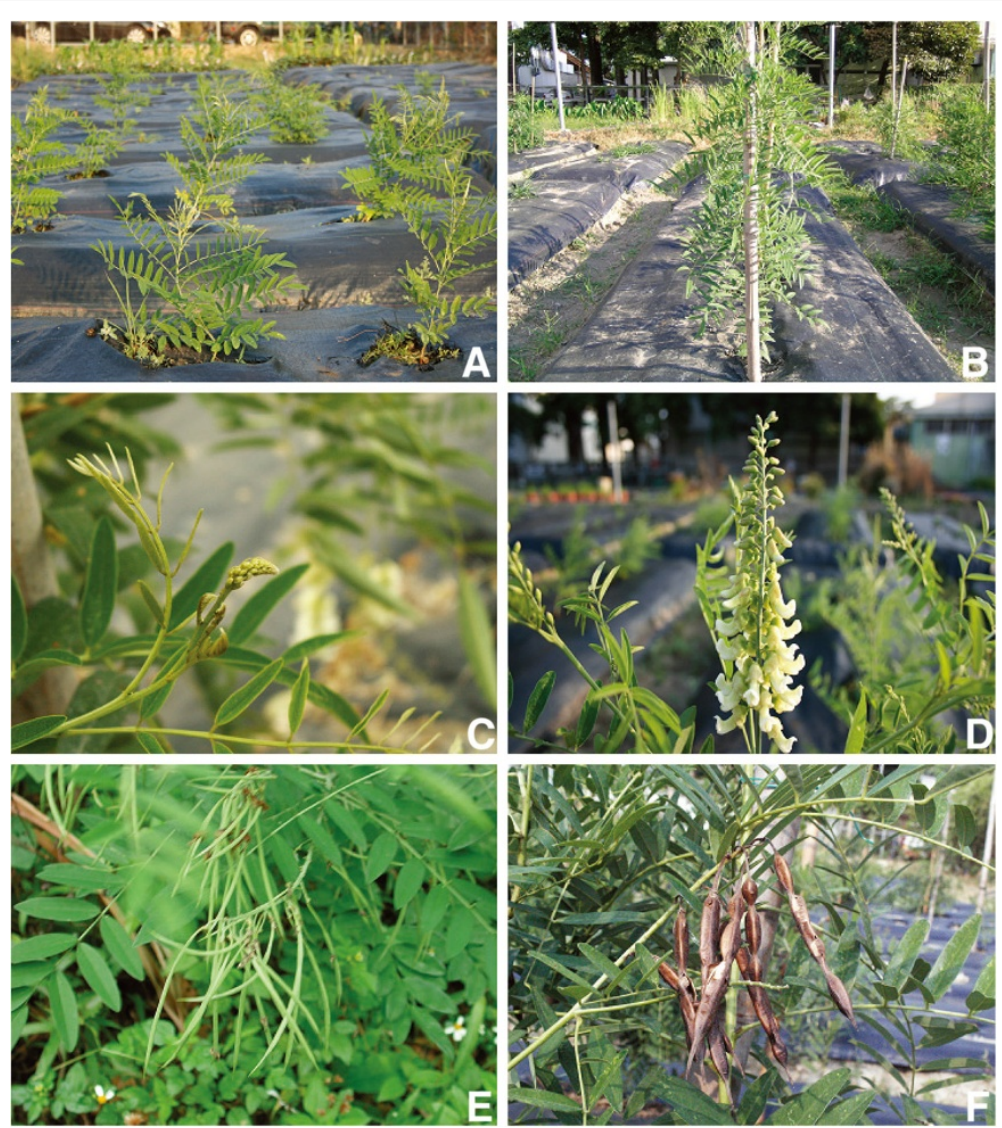

Figure 2 Field-grown S. flavescens plants (Yuli population). (A) early phase of plant growth, (B) mid phase of plant growth, (C) flower bud formation, (D) flower petals expantion, (E) pod formation and (F) mature pods. 
among the populations (Table 2). The highest number of primary branches produced per plant was obtained from Yuli population, followed by the Hualien, Gansu (China) and Danda populations. Plants of the Danda population produced more flowers and pods per inflorescence, and more seeds per pod, but have less 100-seeds weight, than other three populations (Table 2). On the other hand, the plant of Hualien population produced more roots than others.

\section{Microscopic observations}

The transverse sections of roots, stems and leaf tissues of $S$. flavescens populations are similar within each tissue, therefore, only the tissue samples of Yuli population were illustrated in Figure 3A-D. The mature root is almost circular in outline (Figure 3A). Cork is multilayered with a broad and well developed zone comprising of 9 (Yuli) to 12 (Danda) layers (data were determined from enlarged root cross section that were not shown in Figure 3), and the cells are flat in shape. However, cork often split and dropped. Cortex consists of 22 (Yuli) to 28 (Danda) layers (data not presented) of parenchyma cells. Cambium is a distinct zone of two (Yuli) to six (Danda) layers of small meristematic cells. There are 12 (Yuli) to 17 (Gansu) pith rays (data not presented).

The epidermis of $S$. flavescens stem is single layered with outer cuticle (Figure 3B). The cortex consists of 6 (Gansu) to 11 (Hwalien) layers (Figure 3D) of round cortical parenchyma cells. The pith is large and consists of large parenchyma cells.

There is a single layered epidermis on the upper and lower surfaces of the leaf (Figure 3C). The palisade parenchyma in contact with the upper epidermis consists of one to two layers of relatively elongated cells, while the spongy parenchyma in contact with lower epidermis has two to three layers. In the median region of the leaf, there is a large vascular bundle.

\section{Phytochemicals}

Phenols constitute one of the most abundant groups of secondary metabolites, ranging from simple molecules (e.g., phenolic acids) to highly polymerized compounds (e.g., lignins), in plant kingdom. They have been demonstrated to prevent the development of many chronic diseases, which might be associated with their powerful antioxidant and free radical scavenging properties (Manach et al., 2004). In the present study, the amounts of total phenols in the dried roots of S. flavescens varied from 32.38 (Hualien population) to $53.22 \mathrm{mg}$ gallic acid $\mathrm{g}^{-1}$ (Danda population) on dry weight (DW) base (Table 3). The values are considerably higher than the total phenols content (20.8 mg gallic acid DW g ${ }^{-1}$ ) reported by Cai et al. (2004). This could be due to the different S. flavescens populations used between the two studies.

Flavonoids are a subclass of phenols, many of which can alter metabolic processes and have a positive impact on health (Beecher, 2003). The flavonoids regularly introduced with the diet can act as mild pro-oxidants and stimulate the endogenous antioxidant defenses. As shown in Table 3, the contents of flavonoids in the dried roots of S. flavescens populations ranged from 2.39 (Hualien population) to 6.48 (Danda population) $\mathrm{mg} \mathrm{g}^{-1} \mathrm{DW}$. These values are considerably higher than that $\left(0.79 \mathrm{mg} \mathrm{g}^{-1}\right.$ root $\left.\mathrm{DW}\right)$ reported by Gou et al. (2011).

The dried roots of $S$. flavescens also contain about twenty kinds of alkaloids, among them matrine and oxymatrine are the main effective constituents used for disease treatments (Wang et al., 2012). Therefore, only matrine and oxytraine were measured in this study. The matrine and oxymatrine contents were found to be significantly different among the examined S. flavescens populations (Table 3). The population from Gansu (China) had the highest amounts of matrine and oxymatrine, and then followed by the populations from Danda, Yuli and Hualien. Despite the Hualien population produced the

Table 2 The morphological characteristics of S. flavescens populations ${ }^{a}$

\begin{tabular}{lllll}
\hline Characteristics & Gansu & Hualien & Yuli & Danda \\
\hline No. of leaflet & $17.00 \pm 1.90 \mathrm{ab}$ & $19.00 \pm 3.47 \mathrm{a}$ & $17.00 \pm 2.36 \mathrm{ab}$ & $15.00 \pm 2.83 \mathrm{~b}$ \\
Leaflet length $(\mathbf{m m})$ & $33.63 \pm 4.62 \mathrm{~b}$ & $42.40 \pm 4.97 \mathrm{a}$ & $43.12 \pm 4.92 \mathrm{a}$ & $41.61 \pm 4.89 \mathrm{a}$ \\
Leaflet width $(\mathbf{m m})$ & $10.88 \pm 1.82 \mathrm{bc}$ & $12.13 \pm 1.61 \mathrm{ab}$ & $13.37 \pm 1.32 \mathrm{a}$ & $9.56 \pm 0.93 \mathrm{C}$ \\
No. of primary branches & $3.78 \pm 0.42 \mathrm{~b}$ & $4.67 \pm 0.93 \mathrm{ab}$ & $5.00 \pm 0.76 \mathrm{a}$ & $1.89 \pm 0.19 \mathrm{c}$ \\
No. of flower per inflorescence & $33.38 \pm 0.88 \mathrm{~b}$ & $34.34 \pm 1.03 \mathrm{~b}$ & $31.00 \pm 1.45 \mathrm{c}$ & $43.20 \pm 3.23 \mathrm{a}$ \\
No. of pod per inflorescence & $2.50 \pm 0.58 \mathrm{c}$ & $5.67 \pm 1.57 \mathrm{~b}$ & $6.05 \pm 0.97 \mathrm{~b}$ & $9.05 \pm 2.51 \mathrm{a}$ \\
No. of seed per pod & $7.84 \pm 0.69 \mathrm{ab}$ & $7.04 \pm 0.71 \mathrm{~b}$ & $7.95 \pm 0.84 \mathrm{ab}$ & $8.59 \pm 0.27 \mathrm{a}$ \\
100-seed weight (g) & $4.02 \pm 1.07 \mathrm{~b}$ & $4.11 \pm 0.44 \mathrm{~b}$ & $4.60 \pm 0.52 \mathrm{a}$ & $3.60 \pm 0.55 \mathrm{C}$ \\
Dried root weight $(\mathbf{g})$ & $142.45 \pm 26.94 \mathrm{bc}$ & $284.66 \pm 41.40 \mathrm{a}$ & $191.26 \pm 30.02 \mathrm{~b}$ & $122.40 \pm 25.54 \mathrm{C}$ \\
No. of roots per plant & $6.40 \pm 2.07 \mathrm{a}$ & $5.20 \pm 1.64 \mathrm{a}$ & $7.60 \pm 2.06 \mathrm{a}$ & $7.25 \pm 1.58 \mathrm{a}$ \\
Plant height $(\mathbf{c m})$ & $73.06 \pm 19.37 \mathrm{~b}$ & $107.32 \pm 18.03 \mathrm{a}$ & $86.00 \pm 18.16 \mathrm{ab}$ & $75.75 \pm 25.30 \mathrm{~b}$ \\
\hline
\end{tabular}

${ }^{a}$ Means \pm standard errors $(n=4)$ within each column followed by different letters are significantly different at the $P=0.05$ level. 

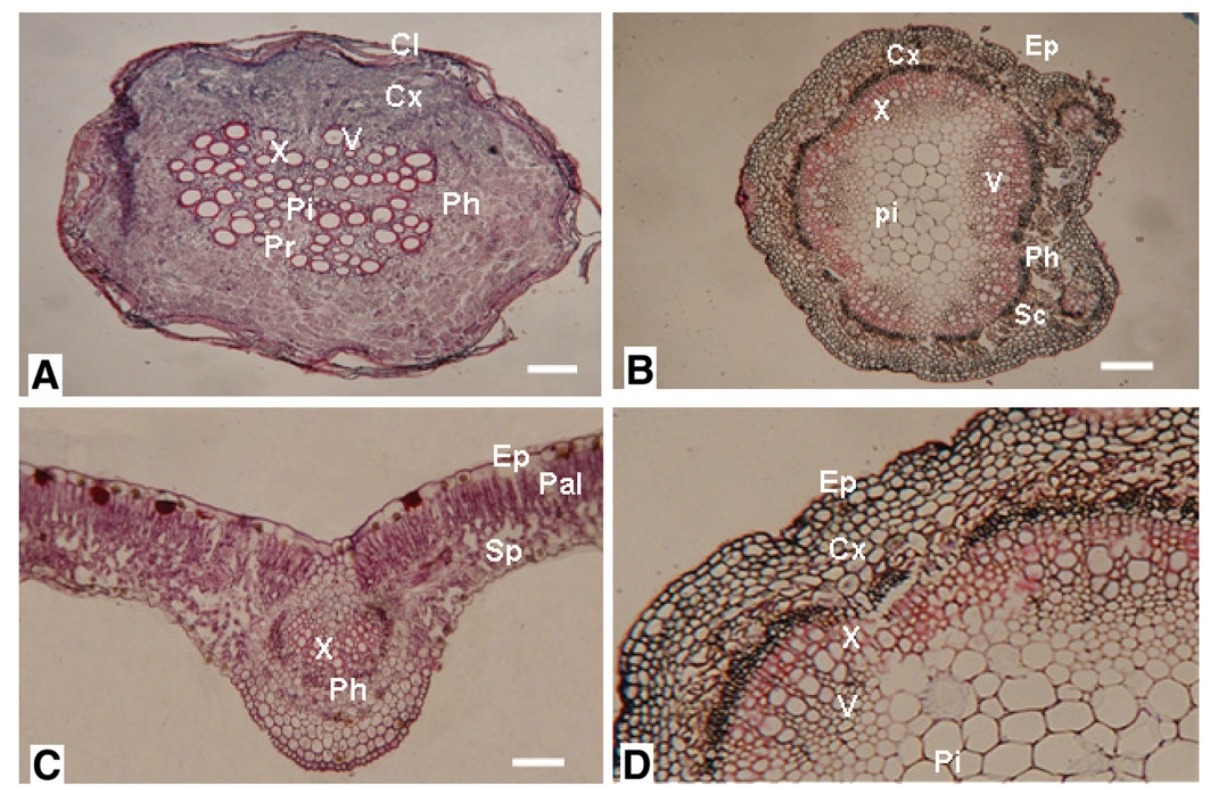

Figure 3 Cross sections of (A) root, (B) stem, (C) leaf and (D) enlarged stem cross section of S. flavescens plants (Yuli population). Cx: cortex, Cl: cork layer, Pi: pith, Pr: pith ray, Ph: phloem, V: vessel, X: xylem, Ep: epidermis, Pal: palisade tissue, Sc: sclerenchyma, Sp: spongy tissue, Bar $=5 \mu \mathrm{m}$.

highest amount of dried root (Table 2), its dried roots had the lowest levels of matrine and oxymatrine among the examined populations (Table 3).

\section{Antioxidant activities}

Several techniques, such as 2,2-diphenyl-1-picrylhydrazyl $(\mathrm{DPPH})$ radicals scavenging, ferric reducing antioxidant power (FRAP) and lipid peroxidation inhibition ability, have been used to determine anti-oxidative activities in selected foods, but each with different specificity and sensitivity (Frankel \& Meyer, 2000). In this study, both FRAP and Trolox equivalent antioxidant capacity (TEAC) were applied to evaluate the anti-oxidative capacity in the roots of $S$. flavescens population. Statistical analyses showed that the $S$. flavescens populations collected from Danda tended to have relatively greater FRAP activity than the other three populations (Table 3). On the other hand, the highest TEAC activity was obtained from the Hualien population, and then followed by Yuli,
Gansu and Danda populations (Table 3). Both FRAP and TEAC are electron transfer-based assay, in which the antioxidant action is simulated by allowing the antioxidants to react with a suitable redox-potential probe (fluorescent or colored oxidizing agent). Nevertheless, FRAP assay does not measure thiol antioxidants such as glutathione (Badarinath et al., 2010). Thus, this difference might partially illustrate why different ranking orders in anti-oxidative capacity were observed among the tested S. flavescens populations by using FRAP and TEAC.

\section{Conclusions}

The S. flavescens populations used in this study were grown from seeds harvested from four different localities. No within-species karyotypic variations were observed among them. All the examined populations have a diploid number of $2 \mathrm{n}=18$, which indicated that the collected populations are cytologically stable. Significant morphological differences were found among the populations; with the population

Table 3 Comparisons of total phenols, flavonoids, matrine, oxymatrine, ferric reducing antioxidant power (FRAP) and trolox equivalent antioxidant capacity (TEAC) in roots of S. flavescens populations ${ }^{a}$

\begin{tabular}{|c|c|c|c|c|c|c|}
\hline Population & $\begin{array}{l}\text { Total phenols } \\
\left.\text { (mg g }{ }^{-1} \mathrm{DW}\right)\end{array}$ & $\begin{array}{l}\text { Flavonoids } \\
\left.\text { (mg g }{ }^{-1} \mathrm{DW}\right)\end{array}$ & $\begin{array}{c}\text { Matrine } \\
\left.\text { (mg g }{ }^{-1} \mathrm{DW}\right)\end{array}$ & $\begin{array}{l}\text { Oxymatrine } \\
\left.\text { (mg g }{ }^{-1} \mathrm{DW}\right)\end{array}$ & $\begin{array}{c}\text { FRAP } \\
\left(\mathrm{mg} \mathrm{g}^{-1} \mathrm{DW}\right)\end{array}$ & $\begin{array}{c}\text { TEAC } \\
\left(\mathrm{mg} \mathrm{g}^{-1} \mathrm{DW}\right)\end{array}$ \\
\hline Gansu, China & $41.49 \pm 2.97 b$ & $4.37 \pm 1.12 b$ & $19.72 \pm 3.13 \mathrm{a}$ & $4.26 \pm 0.82 a$ & $19.52 \pm 1.89 b c$ & $314.90 \pm 8.93 b$ \\
\hline Danda, Taiwan & $53.22 \pm 4.10 \mathrm{a}$ & $6.48 \pm 0.58 a$ & $13.99 \pm 2.60 \mathrm{ab}$ & $1.72 \pm 0.38 b$ & $25.01 \pm 1.72 \mathrm{a}$ & $283.57 \pm 11.81 \mathrm{C}$ \\
\hline Yuli, Taiwan & $35.31 \pm 3.85 c$ & $3.17 \pm 1.83 c$ & $12.75 \pm 2.83 b$ & $1.14 \pm 0.44 b c$ & $23.20 \pm 3.19 a b$ & $364.06 \pm 10.62 a$ \\
\hline Hualien, Taiwan & $32.38 \pm 4.67 c$ & $2.39 \pm 1.14 c$ & $10.14 \pm 1.74 b$ & $0.61 \pm 0.16 c$ & $19.44 \pm 3.59 c$ & $365.42 \pm 9.48 a$ \\
\hline
\end{tabular}

${ }^{a}$ Means \pm standard errors $(n=4)$ within each column followed by different letters are significantly different at the $P=0.05$ level. 
from Hualien produced more roots than the others. However, the lowest levels of matrine and oxymatrine were obtained from the dry root of the Hualien population. The dry root of the population from Gansu (China) had the highest amounts of matrine and oxymatrine. On the other hand, the roots of the Yuli population had the highest ferric reducing antioxidant power and trolox equivalent antioxidant capacity among the examined populations. Thus, the collected S. flavescens populations that show diversity in pharmaceutical and medicinal characteristics have the potential for breeding high-value S. flavescens populations.

\section{Competing interests}

The authors declare that they have no competing interests.

\section{Authors' contributions}

Tzu Che Lin was phd student and responsible for seedlings cultivation, sampling and biochemical analysis. Jih Min Sung and Mau Shing Yeh were codirecdor for experiment design and data presentation in this paper. All authors read and approved the final manuscript.

\section{Author details}

'Department of Agronomy, National Chung Hsing University, Taichung, ROC, Taiwan. ${ }^{2}$ Department of Food Science and Technology, Hungkuang University, Shalu, Taichung, ROC, Taiwan.

Received: 22 June 2012 Accepted: 9 August 2013

Published: 16 January 2014

\section{References}

AbouZid SF, Elsherbeiny GM (2008) Increase in flavonoids content in red onion peel by mechanical shredding. J Med Plants Res 82:258-260

Aguilar-Garcia C, Gavin G, Baragaño-Mosqueda M, Hevia P, Gavino VC (2007) Correlation of tocopherol, tocotrienol, $y$-oryzanol and total polyphenol content in rice bran with different antioxidant capacity assays. Food Chem 102:1228-1232

Badarinath AV, Rao KM, Chetty CMS, Ramkanth S, Rajan TVS, Gnanaprakash K (2010) A review on in-vitro antioxidant method: comparisons, correlations and considerations. Int J PharmTech Res 2:1276-1285

Beecher GR (2003) Overview of dietary flavonoids: nomenclature, occurrence, and intake. J Nutr 133:3248S-3254S

Cai Y, Luo Q, Sun M, Corke H (2004) Antioxidant activity and phenolic compounds of 112 traditional Chinese medicinal plants associated with anticancer. Life Sci 74:2157-2184

Cao HW, Zhang H, Chen ZB, Wu ZJ, Cui YD (2011) Chinese traditional medicine matrine: a review of its antitumor activities. J Med Plants Res 5:1806-1811

Chen X, Yi C, Yang X, Wang X (2004) Liquid chromatography of active principles in Sophora flavescens root. J Chromatogr 812:149-163

De Souza ACC, De Lemos Carvalho PC, Guerra M (2007) Karyotype differentiation among Spondias species and the putative hybrid Umbu-cajá (Anacardiaceae). Bot J Linn Soc 155:541-547

Frankel EN, Meyer AS (2000) The problems of using one-dimensional methods to evaluate multifunctional food and biological antioxidants. J Sci Food Agric 80:1925-1941

Gou J, Zou Y, Ahn J (2011) Enhancement of antioxidant and antimicrobial activities of Dianthus superbus, Polygonum aviculare, Sophora flavescens, and Lygodium japonicum by pressure-assisted water extraction. Food Sci Biotechnol 20:283-287

Jeng TL, Shih YJ, Lai CC, Wu MT, Sung JM (2010) Anti-oxidative characterization of $\mathrm{NaN}_{3}$-induced common bean mutants. Food Chem 119:1006-1011

Jeong T-S, Ryu YB, Kim HY, Curtis-Long MJ, An SJ, Lee JH, Lee WS, Park KH (2008) Low density lipoprotein (LDL)-antioxidant flavonoids from root of Sophora flavescens. Biol Pharm Bull 31:2097-2102

Kasten FH (1956) Chromosomin and the feulgen reaction. J Histochem Cytochem 4:310-317

Levan A, Fredga K, Sandberg A (1964) Nomenclature for centromeric position on chromosomes. Hereditas 52:201-220
Li K, Wang H (2004) Simultaneous determination of matrine, sophoridine and oxymatrine in Sophora Flavescens Ait. by high performance liquid chromatography. Biomed Chromatogr 18:178-182

Lin TC, Yeh MS, Cheng YM, Lin LC, Sung JM (2012) Using ITS2 PCR-RFLP to generate molecular markers for authentication of Sophora flavescens Ait. J Sci Food Agric 92:892-898

Ling JY, Zhang GY, Cui ZJ, Zhang CK (2007) Supercritical fluid extraction of quinolizidine alkaloids from Sophora flavescene Ait. and purification by high-speed counter-current chromatography. J Chromatogr A 1145:123-127

Liu G, Dong J, Wang H, Hashi Y, Chen S (2011) Characterization of alkaloids in Sophora flavescens Ait. by high-performance liquid chromatography-electrospray ionization tandem mass spectrometry. J Pharmaceut Biomed Anal 54:1065-1072

Manach C, Scalbert A, Morand C, Rémésy C, Jiménez L (2004) Polyphenols: food sources and bioavailability. Am J Clin Nutr 79:727-747

Marhold K (2009) IAPT/IOPB chromosome data 8. Taxon 58:1281-1289

Michetti KM, Leonardi PI, Cáceres EJ (2010) Morphology, cytology and taxonomic remarks of four species of Stigeoclonium (Chaetophorales, Chlorophyveae) from Argentina. Phycol Res 58:35-43

Piao X-L, Piao XS, Kim SW, Park JH, Kim HY, Cai S-Q (2006) Identification and characterization of antioxidants from Sophora flavescens. Biol Pharm Bull 29:1911-1915

Safarnejad A, Hosaini SM (2005) Cytogenetic studies in alfalfa (Medicago sativa L.) somaclones following tissue culture. Iran J Rangelands Forests Plant Breed Genet Res 13:209-220

Sharma PC, Gupya PK (1982) Karyotypes in some pulse crops. Nucleus 25:181-185

Wang H, Lu Y, Chen J, Li J, Liu S (2012) Subcritical water extraction of alkaloids in Saphora flavescens Ait. And determination by capillary electrophoresis with field-amplified samples stacking. J Pharmaceut Biomed Anal 58:146-151

Zhao DL, Guo GQ, Wang XY, Zheng GC (2004) In vitro micropropagation of a medicinal plant species Sophora flavescens. Biol Plantarum 47:117-120

doi:10.1186/1999-3110-55-5

Cite this article as: Lin et al.: Karyological, morphological and

phytochemical characteristics of medicinal plants Sophora flavescens

Aiton grown from seeds collected at different localities. Botanical Studies 2014 55:5.

\section{Submit your manuscript to a SpringerOpen ${ }^{\circ}$ journal and benefit from:}

- Convenient online submission

Rigorous peer review

- Immediate publication on acceptance

- Open access: articles freely available online

- High visibility within the field

- Retaining the copyright to your article

Submit your next manuscript at $>$ springeropen.com 